\title{
Emergency peripartum hysterectomy: a retrospective analysis in a tertiary care hospital in Jharkhand, India
}

\author{
Megha Bhagat*, Bratati Moitra
}

Department of Obstetrics and Gynecology, Rajendra Institute of Medical Sciences, Ranchi, Jharkhand, India

Received: 20 May 2018

Accepted: 26 June 2018

*Correspondence:

Dr. Megha Bhagat,

E-mail: drmeghadr@gmail.com

Copyright: () the author(s), publisher and licensee Medip Academy. This is an open-access article distributed under the terms of the Creative Commons Attribution Non-Commercial License, which permits unrestricted non-commercial use, distribution, and reproduction in any medium, provided the original work is properly cited.

\begin{abstract}
Background: Emergency peripartum hysterectomy (EPH) is a rare but a lifesaving procedure done as a last resort to save life of mother. We conducted this study to know the incidence, leading causes, and complications of obstetric hysterectomy.

Methods: Authors conducted a retrospective analysis of all the patients who underwent emergency peripartum hysterectomy from January 2015 to December 2017 at RIMS, Ranchi.

Results: There were 126 emergency peripartum hysterectomies, with deliveries during the same period being 21732 and the rate of EPH was 5.7 per 1000 deliveries. Most common indication for EPH was uterine rupture (54.6\%), followed by uterine atony $(18.2 \%)$ and morbidly adherent placenta $(23.01 \%)$. Most of the patients $(66.67 \%)$ had previous cesarean deliveries. EPH was done following cesarean in $66.67 \%$. Subtotal hysterectomy was done in $88.09 \%$. Intra-operative urinary bladder injury was seen in $11.11 \%$ of the patients.

Conclusions: Uterine rupture and Morbidly adherent placenta continues to be the most common causes for EPH in our population. Multiparity is an important risk factor among patients with rupture uterus. Cesarean delivery and repeat cesarean deliveries are the likely risk factors for EPH.
\end{abstract}

Keywords: Emergency peripartum hysterectomy, Previous cesarean, Uterine rupture

\section{INTRODUCTION}

Emergency peripartum hysterectomy is a rare but a very challenging obstetric procedure. It is done as a last resort to save the life of a parturient mother. It is done during delivery, after delivery both (normal vaginal delivery and caesarean section) and within 42 days of termination of pregnancy. In no other gynecological or obstetrical surgery is the surgeon in as much a dilemma as when deciding to resort to an emergency hysterectomy. On one hand it is the last resort to save a mother's life, and on the other hand, the mother's reproductive capability is sacrificed. Many times, it is a very difficult decision and requires good clinical judgement. Most of the times the operation is carried out when the condition of the patient is too critical to withstand the risks of anesthesia or surgery. Proper timing and meticulous care may reduce or prevent maternal complications. Incidence of emergency peripartum hysterectomy varies from region to region. ${ }^{1}$

Incidence depends on the availability of good antenatal and obstetric care. It also depends on education of the patient and general health care awareness of the society. Incidence also varies with the mode of delivery. EPH (emergency peripartum hysterectomy) following vaginal delivery is constant and varies between $0.1-0.3$ per 1000 vaginal deliveries. ${ }^{1}$ EPH following caesarean section varies widely between $0.17-8.7$ per 1000 caesarean 
deliveries as it depends on other factors like presence of morbidly adherent placenta. ${ }^{1}$

EPH includes hysterectomies done during caesarean section and after vaginal delivery or any time within the puerperium. ${ }^{2} \mathrm{EPH}$ is a very challenging procedure, as the patient would be critically ill and since it is rare, expertise among obstetricians is minimal. Indications for EPH have been changing over years. Uterine atony and rupture uterus are now being replaced by abnormal placentation as a major cause of EPH1. This is because of vigilant care given during labor to prevent prolonged labor and also early management of atonic PPH (postpartum haemorrhage) with uterotonic agents. This change may also be due to the increasing tendency towards caesarean deliveries which predisposes to abnormal placentation. Severe post-partum haemorrhage continues to be the leading cause of maternal deaths accounting for $27.1 \%$ of deaths worldwide. ${ }^{3}$ There has been a steady rise in incidence of post-partum haemorrhage, in spite of there being great advances in availability of better drugs for conservative management of postpartum hemorrhage ${ }^{4}$

A meta-analysis showed that incidence of obstetric hysterectomy has been increasing at the rate of $8 \%$ annually. ${ }^{5}$ Risk factors for $\mathrm{EPH}$ include advanced maternal age, multiparity, previous caesarean, uterine myoma, placenta previa ,induced labor, operative vaginal delivery, caesarean delivery and fetal macrosomia. ${ }^{6}$ Early identification of risk factors, good antenatal and obstetric care, early referral to tertiary centre would certainly help in preventing obstetric hysterectomies and reducing maternal mortality.

Authors conducted this study to know the incidence, patient profile, indications and complications of EPH.

\section{METHODS}

This retrospective and analytical study was carried out in the Department of Obstetrics and Gynaecology, Rajendra Institute of Medical Sciences, Ranchi from January 2015 to December 2017.

\section{Inclusion criteria}

- Patients who suffered severe post-partum haemorrhage (both after normal vaginal delivery and during caesarean section) who did not respond to medical and conservative management, leading to life saving emergency peripartum hysterectomy

- Patients with ruptured uterus of both scared and unscared uterus which could not be repaired, leading to emergency peripartum hysterectomy

- Patients with morbidly adherent placenta, Placenta accreta found during caesarean section

- Patients who underwent hysterectomy for complications following pregnancy termination $\left(1^{\text {st }}\right.$ and $2^{\text {nd }}$ trimester abortion) leading to perforation and sepsis
- Hystrectomy done for cases of uterine inversion following delivery

- Hysterectomy done for cases of Secondary PPH (not controlled by conservative measures) within 42 days of delivery.

\section{Exclusion criteria}

- Hysterectomies performed for gynaecological causes were excluded from the study

- All cases of Rupture uterus in which uterine repair was done.

Patients who underwent Emergency Peripartum Hysterectomy were identified from labour ward registers, OT register. Each case record was analysed in detail with special emphasis on indication, demographic data (age, parity, booking status, referred cases etc.), presence of risk factors like (multiparity, previous caesarean, obstructed labour, instrumental delivery, placental factors, uterine atony, uterine rupture) status of baby, type of operation performed, problems encountered during operation, blood transfusion, post-operative morbidity, and mortality.

\section{Statistical analysis}

Descriptive analyses were carried out to summarize relevant variables.

\section{RESULTS}

\section{Incidence}

There were 126 cases of Emergency peripartum hysterectomy amongst 21732 deliveries during the study period giving an incidence of $0.58 \%$.

Table 1: Incidence of emergency obstetric hysterectomy (EOH).

\begin{tabular}{|l|l|}
\hline Statistical data & Number \\
\hline Total Number of deliveries & 21732 \\
\hline Number of LSCS & 7944 \\
\hline Number of vaginal deliveries & 13788 \\
\hline Number of EPH & 126 \\
\hline Incidence of EPH & $0.58 \%$ \\
\hline
\end{tabular}

\section{Maternal characteristics}

Majority of women were in age group of 21-30 yrs 69.8\%. $3.9 \%$ of women were Primiparous where $64.2 \%$ of women were Para 2 and 3. Remaining $31.7 \%$ of women were grandmultiparous (Table 2).

76 cases were Unbooked $(60.3 \%)$ and 50 cases were Booked $(39.6 \%)$ and most of the cases were referred from periphery 78 cases $(61.9 \%)$ (Table 3$)$. 
Table 2: Demography.

\begin{tabular}{|c|c|c|}
\hline & Emergency Hysterectomy & Incidence \\
\hline \multicolumn{3}{|c|}{ 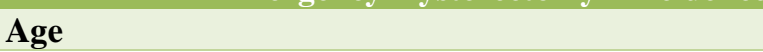 } \\
\hline$<20$ Yrs & 2 & $1.58 \%$ \\
\hline $21-30 \mathrm{Yrs}$ & 88 & $69.8 \%$ \\
\hline $31-40$ Yrs & 36 & $28.5 \%$ \\
\hline \multicolumn{3}{|l|}{ Parity } \\
\hline 1 & 5 & $3.9 \%$ \\
\hline 2 & 48 & $38.1 \%$ \\
\hline 3 & 33 & $26.1 \%$ \\
\hline$>3$ & 40 & $31.7 \%$ \\
\hline
\end{tabular}

Table 3: Antenatal booking.

\begin{tabular}{|lll|}
\hline Booking status & No. & Percentage \\
\hline Unbooked & 76 & 60.3 \\
\hline Booked & 50 & 39.6 \\
\hline
\end{tabular}

Major risk factors identified in patients undergoing EPH were Multiparity (57.9\%) and Previous LSCS $(66,67 \%)$ (Table 4).

Table 4: Identification of risk factors.

\begin{tabular}{|lll|}
\hline Risk Factor & Number & Percentage \\
\hline Multiparity & 73 & 57.9 \\
\hline Previous LSCS & 84 & 66.67 \\
\hline Placental factors & 28 & 22.22 \\
\hline Obstructed labour & 18 & 14.2 \\
\hline Instrumental delivery & 11 & 8.7 \\
\hline
\end{tabular}

Rupture uterus mostly scar rupture $(41.2 \%)$ and morbidly adherent placenta $(23.01 \%)$ were the common indications (Table 5).

Table 5: Indications of emergency peripartum hysterectomy.

\begin{tabular}{|ll|l|}
\hline Indications & Number & Percentage \\
\hline Rupture of scarred uterus & 52 & 41.2 \\
\hline Rupture of unscarred uterus & 17 & 13.4 \\
\hline Atonic PPH & 23 & 18.2 \\
\hline Placenta accreta & 29 & 23.01 \\
\hline Secondary PPH & 2 & 1.5 \\
\hline $\begin{array}{l}\text { Sepsis following uterine } \\
\text { perforation }\end{array}$ & 2 & 1.5 \\
\hline Uterine inversion & 1 & 0.79 \\
\hline
\end{tabular}

\section{Type of operation}

In 111 cases $(88.09 \%)$ Subtotal hysterectomy was done while in 15 cases (11.9\%) total hysterectomy was done due to implantation of placenta in lower segment reaching upto cervix and uncontrolled haemorrhage. Bladder repair was done in 14 cases $(11.11 \%)$.

There were 7 maternal death giving a maternal mortality of $5.55 \%$. It was due to DIC with Septicemia, severe irreversible hypovolemic shock and multiorgan dysfunction. All our patients received blood transfusion and $88 \%$ had over 4-6 units of blood transfusion.

Table 6: Postoperative complications.

\begin{tabular}{|lll|}
\hline Complications & No. of cases & Percent \\
\hline Intraoperative hypotension & 48 & 38.1 \\
\hline Injury to bladder & 14 & 11.11 \\
\hline Febrile illness & 15 & 11.9 \\
\hline ICU admission & 35 & 27.7 \\
\hline Mortality & 7 & 5.55 \\
\hline Septicemia & 4 & 3.17 \\
\hline Perinatal death & 83 & 65.87 \\
\hline DIC & 5 & 3.96 \\
\hline Vesicovaginal fistula & 3 & 2.3 \\
\hline
\end{tabular}

\section{DISCUSSION}

Emergency peripartum hysterectomy is a lifesaving procedure of choice in cases of intractable hemorrhage and catastrophic rupture of uterus. ${ }^{7}$ It is an unequivocal marker of severe acute maternal morbidity. It is associated with high index of maternal mortality and morbidity. In developed countries, the reported incidence of emergency hysterectomy is below $0.1 \%$ of the total normal deliveries performed, while in developing countries, the incidence rates are as high as 1-5/ 1000 of all the deliveries performed. The incidence in the present study is 5.79 per 1000 deliveries. The primary reason for this higher incidence is due to the fact that our hospital is a Tertiary referral centre to most of the primary health care centres in surrounding rural areas of Jharkhand. Majority of the patients are unbooked and delivered outside the health facilities unsupervised or poorly supervised and are referred in a deteriorated state.

The main indications for peripartum hysterectomy in developed countries are uterine atony and abnormal placentation, where as in developing countries, it was rupture of uterus and atony of uterus. ${ }^{8}$ The most common causes of EPH in present study are rupture uterus of unscarred and scarred uterus and morbidly adherent placenta. Uterine rupture remains one of the serious obstetric complications even in modern obstetrics. ${ }^{9}$ Lack of health information, illiteracy, poor antenatal care, poverty, home delivery by birth attendants, increasing incidence of previous caesarean and delay in referrals all contribute to uterine rupture. Previous caesarean section with early conception, injudicious use of oxytocin and trial of labour was the common cause, whereas prolonged obstructed labour was the second common cause. Prevalence of Rupture uterus (both scarred and unscarred) in present study is $69(54.76 \%)$.

A high association of multiparity (57.9\%) with EPH was observed in our study whereas Chawla et al reported incidence of EPH in multiparous women as $82 \% .^{2}$ Ohonsi et al reported 60\% EPH in P5 and above. ${ }^{10}$ 
The most common indication of EPH in present study was rupture uterus $(54.76 \%)$, followed by morbidly adherent placenta $(23.01 \%)$, atonic uterus (18.2\%). Similar high rate of EPH for ruptured uterus were also reported by Archana et al (75\%), Ohonsi et al (73\%). ${ }^{10,11}$ On the other hand, a study from UK 12 reported only $8 \%$ of EPH for the same indication. Owing to ignorance, illiteracy, unbooked status, poor socio-economic status, parturients with high risk pregnancies get only a formal and improper supervision antepartum especially intrapartum at periphery and delayed referral results in poor outcome.

Atonic uterus was contributing $18.2 \%$ to EPH in present study. Ohansi et al, Singh et al and Nazam et al reported the frequency of $6.7 \%, 15.6 \%$ and $16.6 \%$ for the same respectively. ${ }^{10,13,14}$ Contrary to this, Chawla et al reported atony $(25 \%)$ as leading cause for $\mathrm{EPH}^{2}{ }^{2}$ Better management of third stage of labour (AMTSL) with strong effective uterotonic drugs available at periphery might be the cause for lesser incidence of atonic uterus and referrals for the same. Also because of recent advances in medical and conservative surgical measures (efficient uterotonic, compression of uterus, uterine catheters, step-wise devascularization of uterus) that will combat with PPH to save the uterus. Morbidly adherent placenta was seen in only $23.01 \%$ in present study. Chawla et al reported $21 \%$ in their study. ${ }^{2}$ Ohonsi et al observed $13.3 \%$ incidence of the morbidly adherent placenta for EPH. ${ }^{10}$ This is in contrast to the study of UK 12 in which $38 \%$ of cases of EPH were for the indication of morbidly adherent placenta. The prominence of this indication for EPH has been reported globally attributed by increasing caesarean rates. Uterine rupture and morbidly adherent placenta were significantly associated with EPH in the present study that collaborates well with other studies from developing countries this is probably because uterine rupture and morbidly adherent placenta tend to be relatively less amenable to medical and conservative surgical treatments, and land up in radical surgeries like EPH.

In the present study, most of cases had subtotal hysterectomy, as most cases were not fit for anesthesia and surgery and also didn't need total hysterectomy. This finding is similar to that reported in other studies. ${ }^{2,10}$ Subtotal hysterectomy is safer, faster and easier to perform than total hysterectomy.

In Maternal morbidities, pyrexia and wound sepsis were the commonest in present study similar to study by Ohonsi et al. ${ }^{10}$ This is because leading indication of EPH was rupture uterus following prolonged obstructed labour; in association with, trauma, anemia; all these predispose to above morbidities. Need of vaso-pressors in $25 \%$ of cases who presented with shock. All patients needed blood transfusion as incidence of anemia is very high in our region. Maternal mortality in present series was $5.55 \%$ that is lower than that reported by Chawla et al $(18 \%)$ and Ohonsi et al $(13.3 \%))^{2,10}$
High perinatal mortality rate $(65.87 \%)$ found in this study similar to that reported by Ohonsi et al $10(73 \%)$ owing to rupture uterus as commonest cause of EPH in both studies. Chawla et al observed perinatal mortality of $28.6 \%$ in their study because EPH was done for postpartum causes like uterine atony and placental factors mainly. ${ }^{2}$

\section{Table 7: Comparitive incidence of EPH in various} studies.

\begin{tabular}{|c|c|c|c|}
\hline $\begin{array}{l}\text { Name of } \\
\text { study }\end{array}$ & $\begin{array}{l}\text { Incidence } \\
\text { of } \mathrm{EPH} \\
\text { per } \mathbf{1 0 0 0} \\
\text { deliveries }\end{array}$ & Mortality & $\begin{array}{l}\text { Commonest } \\
\text { Indication }\end{array}$ \\
\hline $\begin{array}{l}\text { Shirodker } \\
\text { et } \mathrm{al}^{15}\end{array}$ & 1.6 & $2.22 \%$ & $\begin{array}{l}\text { Rupture } \\
\text { uterus }\end{array}$ \\
\hline Chawla et $\mathrm{al}^{2}$ & 0.3 & $17.7 \%$ & Atonic PPH \\
\hline Patil et al ${ }^{16}$ & 1.46 & $8.6 \%$ & $\begin{array}{l}\text { Rupture } \\
\text { uterus }\end{array}$ \\
\hline Sharma et al ${ }^{17}$ & 3.7 & $60 \%$ & $\begin{array}{l}\text { Morbidly } \\
\text { adherent } \\
\text { placenta }\end{array}$ \\
\hline Kittur et al ${ }^{18}$ & 1.5 & $13.9 \%$ & $\begin{array}{l}\text { Uterine } \\
\text { atony }\end{array}$ \\
\hline Kant et al ${ }^{19}$ & 2.6 & $9.7 \%$ & Atonic PPH \\
\hline $\begin{array}{l}\text { Hoblidar } \\
\text { et } \mathrm{al}^{20}\end{array}$ & 0.7 & $4.8 \%$ & $\begin{array}{l}\text { Uterine } \\
\text { atony }\end{array}$ \\
\hline
\end{tabular}

\section{CONCLUSION}

Rate of EPH is high in our institution with poor maternal and foetal outcomes. The incidence in this part of Jharkhand was found to be significantly high due to referral cases from neighbouring government districts hospitals. Hence only proper awareness, timely referral, restricted use of prostaglandins as inducing agents in hospitals not having facilities for caesarean section and correction of anemia are the key factors to be addressed to this part of the state. Improvement in female literacy levels, prevalence of contraception, increase the number of women receiving antenatal care and giving birth in hospital, delivery facilities supervised by skilled care providers can contribute to reduction in maternal morbidity and mortality. Women who are at high risk for primary postpartum haemorrhage should book for antenatal care and deliver in specialized health care facilities. With increasing rate of caesarean, the incidence of morbidly adherent placenta and rupture uterus and the requirement for EPH is possibly going to increase. Better obstetric care, early referral and reduction in primary caesarean deliveries will definitely help in reducing the need for EPH thereby go a long way in improving maternal health.

\section{ACKNOWLEDGMENTS}

Authors would like to thank Dr Neelam Nalini (Associate Professor), Dr Sonia, Dr Swati, Dr Poonam and Dr Bullu Priya for their support in the study. 
Funding: No funding sources

Conflict of interest: None declared

Ethical approval: Not required

\section{REFERENCES}

1. Lovina SM. Machado. Emergency peripartum hysterectomy: incidence, indications, risk factors and outcome. North Am J Med Sci. 2011;3(8):358-61.

2. Chawla J, Arora CD, Ajmani SN. Emergency Obstetric hysterectomy: a retrospective study from a teaching hospital in North India over eight years. Oman Med J. 2015;30(3):181-6.

3. Say L, Chou D, Gemmill A, Tnncalp Ö, Moller AB, Daniels J, et al. Global causes of maternal death: a WHO systematic analysis. Lancet Glob Health. 2014;2(6):323-33.

4. Cameron CA, Roberts CL, Olive EC, Ford JB, Fischer WE. Trends in postpartum hemorrhage. Aust N Z J Public Health. 2006;30(2):151-6.

5. Tunçalp Ö, Hindin MJ, Souza JP, Chou D, Say L. The prevalence of maternal near miss: a systematic review. Int J Obstetr Gynaecol. 2012;119(6):653-61.

6. Carvalho JF, Cubal A, Torres S, Costa F, da Carmo O. Emergency peripartum hysterectomy: a 10- year review. International Scholarly Research Network Emergency Medicine, 2012. Available at http://www.hindawi.com/journals/isrn/2012/721918/.

7. Anuradha C, Vani JY, Aruna V. Emergency peripartum hysterectomy - one year study in labour ward Obstetrics and Gynaec department Guntur Medical College, Guntur. (2014). IOSR J Nursing Health Science (IOSR-JNHS). 2014;4(2)Ver.II:26-8.

8. Pandher DK, Sehgal A, Aggarwal N. Frequency, indications and maternal outcome in obstetric hysterectomy in a tertiary care centre in India. JK Science. 2015;17(1):8-12.

9. Abha S, Shrivastava C. Uterine Rupture: Still a Harsh Reality. J Obstet Gynecol India. 2015;65(3):158-61.

10. Abiodun O, Hassan O. Emergency peripartum hysterectomy in a developing country. J Obstet Gynaecol Can. 2012;34(10):954-60.

11. Archana K, Sahay PB. A clinical review of emergency obstetric hysterectomy. J Obstet Gynaecol India. 2009;59:427-31.
12. Knight M, UKOSS. Peripartum hysterectomy in the UK: management and outcomes of the associated haemorrhage. BJOG: Int J Obstetr Gynaecol. 2007;114(11):1380-7.

13. Singh R, Nagrath A. Emergency obstetric hysterectomy-a retrospective study of 54 cases over a period of 5 years. J Obstet Gyneco India. 2005;55:428-30.

14. Nazam R, Bansal P, Sharma R, Agrawal D. Emergency obstetrics hysterectomy: a retrospective study at a Tertiary Care Hospital. J Clin Diagn Res. 2010;(4):2864-8.

15. Shirodker SD, Pandey A, Yadav S. Emergency obstetric hysterectomy: review at a tertiary care hospital. Int J Reprod Contracept Obstetr Gynecol. 2016;5(11):3811-4.

16. Patil R, Dave A. Emergency Peripartum hysterectomy: a retrospective study at a tertiary care hospital. Int J Reprod Contracept Obatet Gynecol. 2016;5(5):1322-6.

17. Sharma B, Saxena N, Gupta V. A retrospective study of emergency obstetric hysterectomy in a tertiary care center for a period of 5 years. Int $\mathbf{J}$ Reprod Contracept Obstet Gynecol. 2016;5(11): 3778-81.

18. Kittur S, Swetha D. Emergency peripartum hysterectomy- a study in tertiary care center and medical college in Hubli, North Karnatka, India. Int J Reprod Contracept Obstet Gynecol. 2016;5(4):10971101.

19. Kant A, Nadhwani K. Emergency Obstetric hysterectomy. J Obstet Gynecol India. 2005;55(2):132-4.

20. Hoblidar S, KS Sunil, DM Ratnamala.Emergency peripartum hysterectomy: a retrospective study of 7 years. Int $\mathbf{J}$ Reprod Contracept Obstet Gynecol.2016;5(9):3112-3115.

Cite this article as: Bhagat M, Moitra B. Emergency peripartum hysterectomy: a retrospective analysis in a tertiary care hospital in Jharkhand, India. Int J Reprod Contracept Obstet Gynecol 2018;7:3179-83. 